\title{
Role of Coenzyme Q10 in Prophylaxis of Myocardial Infarction
}

\author{
Iftikhar Ali Shah ${ }^{1}$, Mubeen Memon ${ }^{2}$, Sheeba Ansari ${ }^{3}$, Ratan Kumar ${ }^{4}$, Sultan A. Chandio ${ }^{5}$, Shahid H. \\ Mirani ${ }^{6}$, Amber Rizwan ${ }^{7}$
}

1. Internal Medicine, Ghulam Muhammad Mahar Medical College and Hospital, Sukkur, PAK 2. Pulmonology, Liaquat University of Medical and Health Sciences, Jamshoro, PAK 3. Internal Medicine, Liaquat University of Medical and Health Sciences, Jamshoro, PAK 4. Internal Medicine, Civil Hospital Khairpur, Khairpur, PAK 5. Medicine, Shaheed Mohtarma Benazir Bhutto Medical University Larkana, Larkana, PAK 6. Surgery, Ghulam Muhammad Mahar Medical College, Sukkur, PAK 7. Family Medicine, Jinnah Post Graduate Medical Center, Karachi, PAK

Corresponding author: Amber Rizwan, amber_aljazeera109@hotmail.com

\section{Abstract}

Introduction: Coenzyme Q10 (CoQ10) has a potential role in reducing the risk of myocardial infarction by slowing the progression of atherosclerosis and improving ischemia. In this study, we will assess the role of coenzyme Q10 in prophylaxis for reducing myocardial infarction and mortality related to myocardial infarction.

Methods: This open-label two open placebo-controlled randomized clinical trial was conducted in a tertiary care hospital in Sukkur, Pakistan from April 2016 to September 2019. Eight hundred nighty-two (892) patients with clinically diagnosed and documented evidence of hypertension were enrolled in the study from the outpatient department. Participants were randomized into two groups by 1:1 ratio using an online randomizer software, Research Randomizer (https://www.randomizer.org/). Group A received $100 \mathrm{mg}$ coenzyme Q10 daily (coenzyme Q10 group) in addition to standard therapy and group B received standard therapy only (placebo group).

Results: Participants who received coenzyme Q10 had fewer incidence of non-fatal myocardial infarction over 12 months ( $5.4 \%$ vs $8.4 \%$ ) with relative risk reduction of 2.92 (confidence interval 95\%, 0.55-2.76). The number needed to treat to prevent one non-fatal myocardial infarction was 34. Participants who received coenzyme Q10 had fewer incidence of fatal myocardial infarction over 12 months (1.5\% vs 3.1\%) with relative risk reduction of 1.65 (confidence interval 95\%, 0.39-3.69). Number needed to treat to prevent one fatal myocardial infarction was 60 .

Conclusion: According to this study, coenzyme Q10 reduced the incidence of fatal and non-fatal myocardial infarctions. Clinicians should consider adding coenzyme Q10 to the treatment regimen of high-risk patients of myocardial infarction. We suggest coenzyme Q10 may be an effective prophylactic agent in patients at risk of myocardial infarction and it may help in reducing burden on the health care system.

Review began 01/21/2021 Review ended 01/22/2021 Published 02/04/2021

\section{() Copyright 2021}

Shah et al. This is an open access article distributed under the terms of the Creative Commons Attribution License CC-BY 4.0., which permits unrestricted use, distribution, and reproduction in any medium, provided the original author and source are credited.
Categories: Cardiology, Internal Medicine

Keywords: coenzyme q10, prophylaxis, myocardial infarction

\section{Introduction}

Coenzyme Q10 (CoQ10), which is synthesized in the inner mitochondrial membrane, is an essential compound of the human body [1]. CoQ10 is a key component of the electron transport chain in mitochondria necessary for adenosine triphosphate (ATP) production [2]. It also transfers electrons from complexes I and II to complex III in the inner mitochondrial membrane [2].

CoQ10 may have a plausible role in prevention and treatment of heart ailment, as it improves cardiac cellular bioenergetics [3,4]. CoQ10 inhibits progression of atherosclerosis by limiting oxidation of lowdensity lipoprotein (LDL). It also plays a role in improving ischemia and reduces the risk of reperfusion injury of coronary revascularization [5]. The prevalence and healthcare cost of cardiovascular diseases are increasing every year; hence, it is important that molecules that play a role in preventing cardiovascular diseases should be studied [6]. In this study, we will assess the role of coenzyme Q10 in prophylaxis for reducing myocardial infarction and mortality related to myocardial infarction.

\section{Materials And Methods}

This open-label two open placebo-controlled randomized clinical trial was conducted in a tertiary care hospital in Sukkur Pakistan from April 2016 to September 2019. Eight hundred nighty-two (892) patients with clinically diagnosed and documented evidence of hypertension were enrolled in the study from the outpatient department. Ethical review board approval from Ghulam Muhammad Mahar Medical College was 


\section{Cureus}

taken before enrollment of patients (approval GMMMC/IRB-OfC/2016-82). Patients were enrolled using a consecutive convenient non-probability sampling technique. To nullify the effect of different treatment used in management of hypertension, patients only on angiotensin converting enzyme inhibitor (ACEi) in combination with hydrochlorothiazide for hypertension, rosuvastatin for hypercholesterolemia and aspirin for inhibiting platelet aggregation were enrolled. Participants were randomized into two groups by 1:1 ratio using an online randomizer, Research Randomizer (https://www.randomizer.org). Group A received $100 \mathrm{mg}$ coenzyme Q10 daily twice a day (coenzyme Q10 group) in addition to standard therapy and group B received standard therapy only (placebo group).

The patients' characteristics such as age, gender, history of smoking, blood pressure, previous history for myocardial infarction, and family history for myocardial infarction were noted in the self-structured questionnaire. Patients were followed up for 12 months or for development of myocardial infarction in the outpatient department. Myocardial infarction (MI) was diagnosed based on clinical symptoms, cardiac markers such as troponin, and electrocardiogram changes. Thirty-eight (38) and twenty-nine (29) participants in co-enzyme Q10 and placebo, respectively, were lost to follow up and were not included in the final analysis.

Statistical analysis was done using Statistical Package for Social Sciences (SPSS) version 23 (IBM Corp., Armonk, NY, USA). Continuous variables were analyzed via descriptive statistics and were presented as mean and standard deviation (SD) while categorical variables were presented as percentages and frequencies. Relative risk reduction (RRR) and number needed to treat were calculated via an online calculator (MedCalc Statistical Software; MedCalc Software bv, Ostend, Belgium; https://www.medcalc.org) using 95\% confidence interval. Survival probability will be plotted on Kaplan Meier graph. The log rank test was used to calculate the chi-square (X2) for each event time for each group. A p-value of less than 0.05 meant that there is a difference between the two groups and the null hypothesis is void.

\section{Results}

Eight hundred twenty-five (825) participants completed the study, 408 in the coenzyme Q10 group and 417 in the placebo group. There was no difference in demographics and risk factor profile between the two groups (Table 1).

\begin{tabular}{|c|c|c|c|}
\hline Characteristics & Coenzyme Q10 Group (408) & Placebo Group (417) & P-value \\
\hline Age in years (Mean $\pm S D$ ) & $51 \pm 14$ & $52 \pm 16$ & NS \\
\hline Male (\%) & $234(57.4 \%)$ & $248(59.5 \%)$ & NS \\
\hline Smoking (\%) & $131(32.1 \%)$ & $121(29.0 \%)$ & NS \\
\hline Diabetes (\%) & $102(25.0 \%)$ & $98(23.5 \%)$ & NS \\
\hline Hypercholesterolemia (\%) & $252(61.8 \%)$ & $269(64.5 \%)$ & NS \\
\hline Body Mass Index greater than $25 \mathrm{~kg} / \mathrm{m}^{2}(\%)$ & $201(49.3 \%)$ & $199(47.7 \%)$ & NS \\
\hline Previous history of Acute myocardial Infarction (\%) & $22(5.4 \%)$ & $25(6.0 \%)$ & NS \\
\hline Family history of Acute Myocardial Infarction (\%) & $10(2.5 \%)$ & $09(2.2 \%)$ & NS \\
\hline \multicolumn{4}{|l|}{ TABLE 1: Characteristics of Participants } \\
\hline \multicolumn{4}{|c|}{ Abbreviation: SD, standard deviation. NS, non-significant, kg: kilogram, m2: square meter } \\
\hline
\end{tabular}

Participants who received coenzyme Q10 had fewer incidence of non-fatal myocardial infarction over 12 months (5.4\% vs $8.4 \%$ ) with relative risk reduction of 2.92 (confidence interval 95\%, 0.55-2.76). The number need to treat to prevent one non-fatal myocardial infarction was 34. Participants who received coenzyme Q10 had fewer incidence of fatal myocardial infarction over 12 months (1.5\% vs 3.1\%) with relative risk reduction of 1.65 (confidence interval 95\%, 0.39-3.69). The number need to treat to prevent one fatal myocardial infarction was 60 . 


\section{Cureus}

\begin{tabular}{|c|c|c|c|c|}
\hline Adverse Outcome & $\begin{array}{l}\text { Coenzyme Q10 Group } \\
\text { (408) }\end{array}$ & $\begin{array}{l}\text { Placebo Group } \\
(417)\end{array}$ & $\begin{array}{l}\text { Relative Risk Reduction (CI, } \\
95 \%)\end{array}$ & $\begin{array}{l}\text { Number Need to } \\
\text { treated }\end{array}$ \\
\hline Fatal Myocardial Infarction & 06 (1.5\%) & 13 (3.1\%) & $1.65(0.39-3.69)$ & 60 \\
\hline $\begin{array}{l}\text { Non-Fatal Myocardial } \\
\text { Infarction }\end{array}$ & $22(5.4 \%)$ & 35 (8.4\%) & $2.92(0.55-2.76)$ & 34 \\
\hline
\end{tabular}

TABLE 2: Adverse Outcomes in Both Groups

Cl: Confidence Interval

As per Kaplan-Meier curve for non-fatal myocardial infarction, the log rank rest for the data in our study was $\mathrm{p}$ value $=0.09$; thus the two curves were not statistically significantly different (Figure 1 ).

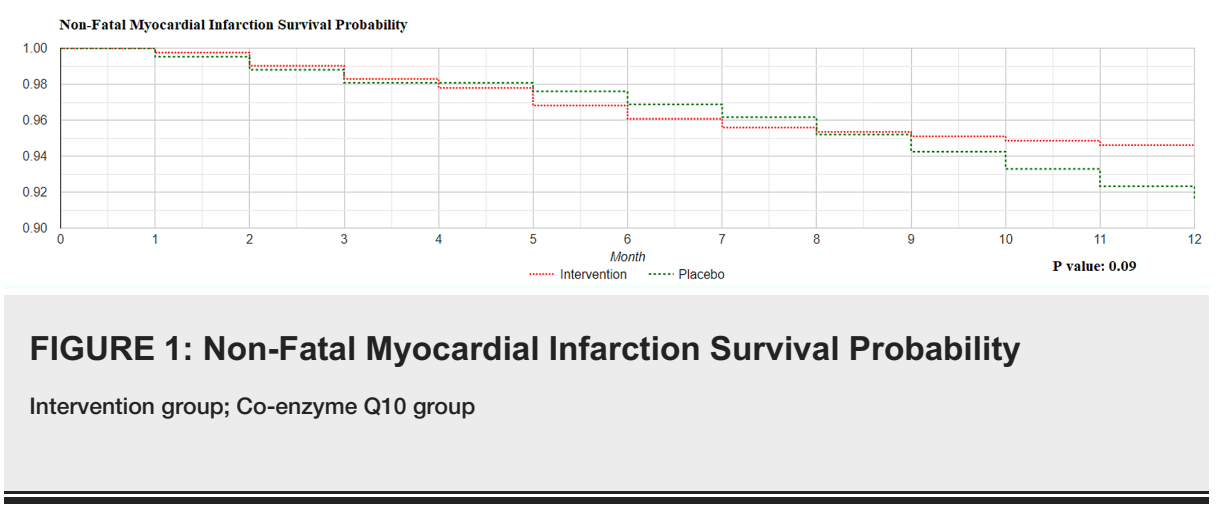

As per Kaplan-Meier curve for fatal myocardial infarction, the log rank rest for the data in our study was $p$ value $=0.11$; thus the two curves were not statistically significantly different (Figure 2).

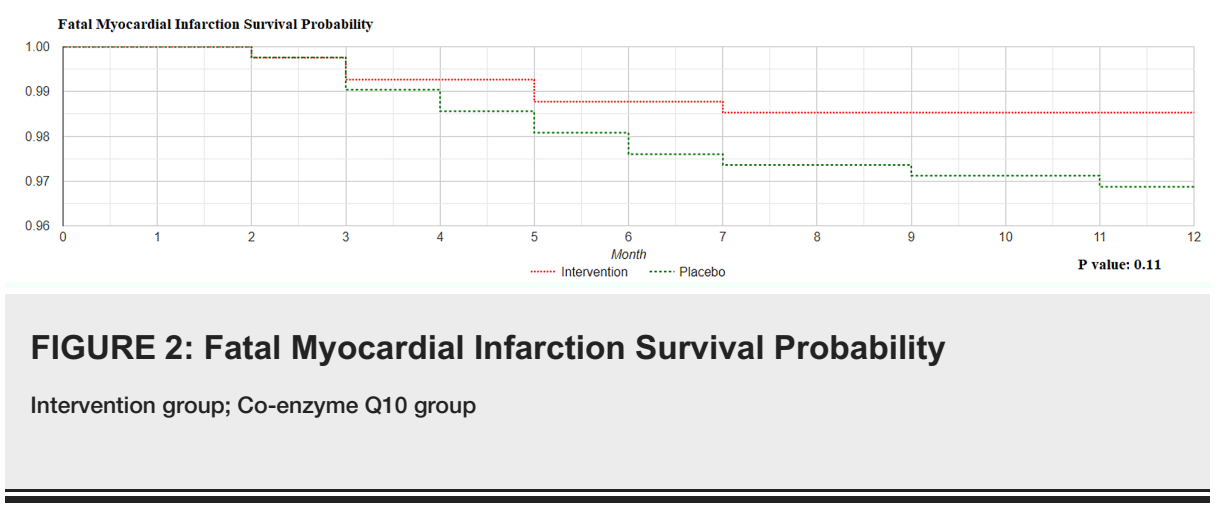

\section{Discussion}

According to this study, coenzyme Q10 reduces the risk of fatal and non-fatal myocardial infarction. Eleawa et al. also postulated that CoQ10 may be an effective prophylactic to prevent myocardial infarction (MI) and $\mathrm{MI}-$ induced cardiac changes. They found that coenzyme Q10 protects against the reinfarction in myocardial infarction. It also reduces infarct area, inflammation, and oxidative stress while normalizing left ventricular hemodynamics after MI [7]. CoQ10 (ubiquinone) plays an important role to prevent the depletion of ATP as an electron carrier in the mitochondrial respiratory chain and in oxidative phosphorylation [8]. With age, endogenous synthesis of CoQ10 in the body declines, therefore it is recommended that elderly people take CoQ10 as a supplement [9]. Kalen et al. found that $75 \%$ of ischemic heart disease patients have low levels of $\mathrm{CoQ} 10$ in the plasma [9]. These cardioprotective effects of CoQ10 are due to its antioxidant effect and its ability to generate ATP $[10]$.

Coenzyme Q10 also plays a role in various other cardiovascular disease and events. Coenzyme Q10 reduces admission in heart failure and reduces the episodes of pulmonary edema in heart failure [11]. Munkholm et al. found that coenzyme Q10 improves the stroke index and capillary wedge pressure [12]. Berman et al. found that coenzyme Q10 improves 6 minute walk time in patients with heart failure [13]. Pourmoghaddas et al. in their study found that supplement of coenzyme Q10 is associated with improved ejection fraction [14]. 
Mortensen et al. found that supplement of coenzyme Q10 reduces the risk of all cause-death, worsening of heart failure, and cardiovascular death [15].

To the best of our knowledge, this is the first study in a local setting that studies the role of prophylaxis against myocardial infarction. The study has its limitation as well. First, since it was single-center study, sample size diversity was reduced. Second, participants were not followed post-MI, hence the role of coenzyme Q10 in preventing MI induced could not be studied in detail.

\section{Conclusions}

In this study, coenzyme Q10 reduced the incidence of fatal and non-fatal myocardial infarctions. Clinicians should consider adding coenzyme Q10 to the treatment regimen of high-risk patients of myocardial infarction. We suggest coenzyme Q10 may be an effective prophylactic agent in patients at risk of myocardial infarction and it may help in reducing the burden on health care systems. Using coenzyme Q10 as a supplement will improve the quality of life of such patients.

\section{Additional Information}

\section{Disclosures}

Human subjects: Consent was obtained or waived by all participants in this study. Ghulam Muhammad Mahar Medical College issued approval GMMMC/IRB-OfC/2016-82. Animal subjects: All authors have confirmed that this study did not involve animal subjects or tissue. Conflicts of interest: In compliance with the ICMJE uniform disclosure form, all authors declare the following: Payment/services info: All authors have declared that no financial support was received from any organization for the submitted work. Financial relationships: All authors have declared that they have no financial relationships at present or within the previous three years with any organizations that might have an interest in the submitted work. Other relationships: All authors have declared that there are no other relationships or activities that could appear to have influenced the submitted work.

\section{References}

1. Quinzii CM, Lopez LC, Von-Moltke J, et al.: Respiratory chain dysfunction and oxidative stress correlate with severity of primary COQ10 deficiency. FASEB J. 2008, 22:1874-1885. 10.1096/fj.07-100149

2. Deichmann R, Lavie C, Andrews S: Coenzyme Q10 and statin-induced mitochondrial dysfunction. Ochsner J. 2010, 10:16-21.

3. Severino P, D'Amato A, Pucci M, et al.: Ischemic heart disease and heart failure: role of coronary ion channels. Int J Mol Sci. 2020, 21:3167. 10.3390/ijms21093167

4. Cellular Aspects of Smooth Muscle Function . Kayo CY, Carsten ME (ed): Cambridge University Press, Cambridge; 2005. 10.1017/CBO9780511759383

5. Kumar A, Kaur H, Devi P, Mohan V: Role of coenzyme Q10 (CoQ10) in cardiac disease, hypertension and Meniere-like syndrome. Pharmacol Ther. 2009, 124:259-68. 10.1016/j.pharmthera.2009.07.003

6. Zozina VI, Covantev S, Goroshko OA, Krasnykh LM, Kukes VG: Coenzyme q10 in cardiovascular and metabolic diseases: current state of the problem. Curr Cardiol Rev. 2018, 14:164-174. 10.2174/1573403X14666180416115428

7. Eleawa SM, Alkhateeb M, Ghosh S, Al-Hashem F, Shatoor AS, Alhejaily A, Khalil MA: Coenzyme Q10 protects against acute consequences of experimental myocardial infarction in rats. Int J Physiol Pathophysiol Pharmacol. 2015, 20:1-13.

8. Liehn EA, Postea O, Curaj A, Marx N: Repair after myocardial infarction, between fantasy and reality: the role of chemokines. J Am Coll Cardiol. 2011, 58:2357-2362. 10.1016/j.jacc.2011.08.034

9. Kalén A, Appelkvist EL, Dallner G: Age-related changes in the lipid compositions of rat and human tissues . Lipids. 1989, 24:579-584. 10.1007/BF02535072

10. Witte KK, Nikitin NP, Parker AC, et al.: The effect of micronutrient supplementation on quality-of-life and left ventricular function in elderly patients with chronic heart failure. Eur Heart J. 2005, 26:2238-2244. 10.1093/eurheartj/ehi442

11. Morisco C, Trimarco B, Condorelli M: Effect of coenzyme Q10 therapy in patients with congestive heart failure: a long-term multicenter randomized study. Clin Investig. 1993, 71:134-136. 10.1007/BF00226854

12. Munkholm H, Hansen HH, Rasmussen K: Coenzyme Q10 treatment in serious heart failure . Biofactors. 1999, 9:285-289. 10.1002/biof.5520090225

13. Berman M, Erman A, Ben-Gal T, et al.: Coenzyme Q10 in patients with end-stage heart failure awaiting cardiac transplantation: a randomized, placebo-controlled study. Clin Cardiol. 2004, 27:295-299. 10.1002/clc.4960270512

14. Pourmoghaddas M, Rabbani M, Shahabi J, Garakyaraghi M, Khanjani R, Hedayat P: Combination of atorvastatin/coenzyme Q10 as adjunctive treatment in congestive heart failure: a double-blind randomized placebo-controlled clinical trial. ARYA Atheroscler. 2014, 10:1-5.

15. Mortensen SA, Rosenfeldt F, Kumar A, et al.: The effect of coenzyme Q10 on morbidity and mortality in chronic heart failure: results from Q-SYMBIO: a randomized double-blind trial. JACC Heart Fail. 2014, 2:641-649. 10.1016/j.jchf.2014.06.008 